\title{
Ties in Tough Times: How Social Capital Helps Lower-Income Jewish Parents Weather the Economic Hardship of COVID-19
}

\author{
Ilana M. Horwitz ${ }^{1}$ (D) Sasha Lascar ${ }^{2}$
}

Received: 21 October 2020 / Accepted: 28 June 2021 / Published online: 21 July 2021

(c) Springer Nature B.V. 2021

\begin{abstract}
In this exploratory study, we examined how social ties helped lower-income Jewish parents in the Greater Philadelphia area weather the COVID-19 pandemic. We interviewed 36 parents who self-identified as Jewish, had at least one school-age child, and earned less than the median Jewish household income in the Philadelphia area. We analyzed the data through the lens of social capital, focusing on three forms: bonding, bridging, and linking social capital. Unlike in weather-related disasters, where social capital yields crucial physical help, the social distancing requirements of the COVID-19 pandemic changed how social capital functions. Parents with strong social ties in the Jewish community were able to connect to people and institutions of power, such as rabbis and Jewish organizations, who provided valuable material resources while families sheltered in place. We describe how people develop relational ties by doing something with and for a social group, and discuss how extended periods of social distancing can threaten the flow of social capital.
\end{abstract}

Keywords COVID-19 · Social capital · Jewish Federation · Low-income · Parents · Interviews

\section{Introduction}

In March 2020, social activity in the United States came to a halt as millions of parents and their children sheltered in place to avoid spreading and contracting COVID-19. Tanya ${ }^{1}$ was one of these parents. In the ensuing four months, Tanya, her husband, and their six children barely left their Philadelphia home. Prior to 1 All names are pseudonyms.

Ilana M. Horwitz

ihorwitz@tulane.edu

1 Jewish Studies Department, Tulane University, New Orleans, LA, USA

2 Stanford University, Stanford, CA, USA 
COVID-19, Tanya, who has a bachelor's degree in elementary education, worked half days as a teacher, earning about $\$ 12,500$ over the course of the academic year. She also earned an additional \$5000 a year through babysitting. When COVID-19 hit, Tanya's school paid her through the end of the school year, but she lost all of her babysitting income. Her reduced wages proved to be especially difficult as she had already taken off several months in early 2020 due to an illness and had just resumed working and earning an income. COVID-19 did not affect her husband's job as a food distributor (where he earns about $\$ 25,000$ a year), yet the pandemic still left them with less than $\$ 40,000$ to shelter and feed their family of eight.

Tanya was not alone. As businesses shut down, millions of Americans became unemployed. Across the United States, the impact of COVID-19 has fallen most heavily on lower-income adults - a group that was feeling significant financial pressure well before the current crisis. In April 2020, 43\% of US. adults said that they or someone in their household had lost a job or taken a pay cut due to the outbreak, up from $33 \%$ in the latter half of March. Among lower-income adults, an even higher share $(52 \%)$ said they or someone in their household had experienced this type of job upheaval (Pew Research Center 2020).

In addition to being among the hardest hit by the economic fallout from COVID19, lower-income adults like Tanya were less prepared to withstand a financial shock than those with higher incomes. Only about one in four (23\%) say they have set aside rainy day funds that would cover their expenses for three months in case of an emergency, compared with $48 \%$ of middle-income and $75 \%$ of upper-income adults (Pew Research Center 2020). In April 2020, over half (53\%) of lower-income adults expected to have trouble paying some of their bills that month. Most of these lowerincome adults would not be able to cover their expenses for three months by borrowing money, using savings, selling assets, or borrowing from friends or family (Pew Research Center 2020). ${ }^{2}$ The long-lasting nature of the COVID-19 pandemic, including a multi-month shelter-in-place order, meant that low-income adults were at high risk of experiencing housing and food insecurity. Like millions of Americans, Tanya could not turn to her parents, siblings, or friends for financial support. But unlike most Americans, Tanya had non-familial social ties through her Jewish social networks. How did social ties to other Jews help Tanya and other low-income Jews weather the COVID-19 pandemic?

Although religious and ethnic organizations like Jewish federations are one potential source of financial support for low-income Jews during economic disasters wrought by events like a pandemic-especially those Jews who cannot turn to friends and family - such groups have received very little attention in the literature. In a recent literature review, Sheikhi et al. (2020) found that religious organizations play a vital role in providing disaster relief to communities after weather-related disasters, which generally decimate physical infrastructure in confined regions. However, much less is known about how religious (and ethnic) organizations might

\footnotetext{
2 The same 2020 Pew research study found that middle-income and upper-income adults were better prepared to weather the financial crisis: about a quarter of middle-income adults and only $11 \%$ of those in the upper-income tier expected to have trouble paying their April 2020 bills (Pew Research Center 2020).
} 
support people through a pandemic-induced economic crisis affecting the entire nation. We also know very little about the role that Jewish organizations play in providing disaster relief, as most studies of religious-based disaster recovery focus on churches (e.g., Cain and Barthelemy 2008; Rivera and Nickels 2014). Finally, existing studies tend to examine the supply side of disaster relief rather than the demand side. For example, Holcombe (2010) interviewed religious leaders to investigate how Houston-based religious congregations provided aid after Hurricane Katrina. Currently, we know very little about the people who need aid and what it takes to get such aid.

To begin filling the gap in the literature, we look at the demand side of economic relief during a pandemic by examining lower-income Jewish parents in a large metropolitan area. We interviewed 36 parents who self-identified as Jewish, had at least one school-age child, and had a household income of $\$ 75,000$ or less (which is below the median Jewish household income in Philadelphia). This exploratory study tells the story of how social ties helped lower-income Jews in tough times.

\section{Social Capital}

Social capital exists in the relations between and among people. It describes the ability of actors to secure benefits by virtue of membership in social networks or other social structures (Bourdieu 1986; Coleman 1988). Scholars have identified three distinct manifestations of social capital: bonding, bridging (Portes 1998; Putnam 2000), and linking social capital (Poortinga 2012; Szreter and Woolcock 2004; Woolcock 2001). Bonding social capital refers to relationships among members of a network who are similar in some form (Putnam 2000). These are "horizontal" and "inward-looking" social networks that reinforce exclusive identities and homogeneous groups-trusting and cooperative relations between people who share social identities. This could be family members or people who are unrelated but still part of the same social groups. Relationships with others facilitate the exchange of obligations or credit slips-I will do this favor for you today and one day you will repay me by doing something for me. This occurs most often when levels of trust are high. When there is bonding social capital, information flows within the social structure, since relationships serve as information channels. When we have trusting relationships with people, we can access information. This is crucial because obtaining information is costly-it requires people to invest time that they often don't have. Bonding capital flows more readily through networks that have closure, meaning that everyone in a network is connected such that no one can escape the notice of others. In closed networks, it is much easier to promote norms and trust because there are enough people who all want to promote the same norms and can combine forces to make that happen. Halachic observance is a norm in Orthodox Jewish communities, and those who deviate from it are likely to suffer social consequences. For example, if parent A sees parent B breaking the laws of kashrut (Jewish dietary laws) by eating a cheeseburger at a fast-food restaurant, parent A would be hesitant to send their child over to play at parent B's house because they don't trust them to have kosher food. Similarly, if a member of an Orthodox Jewish community defects on an obligation to another community member, perhaps by not coming to help make a 
minyan (a quorum of ten people) while someone is sitting shiva (week-long mourning period), thereby precluding them from saying the Mourner's Kaddish, they risk sanctions (e.g., in the form of their reputation) not just from the mourner but from the larger community.

Bridging social capital refers to relationships among people who are dissimilar, perhaps by age or socioeconomic status. Like bonding capital, bridging social capital tends to be horizontal because relationships occur between people with similar levels of power. The key difference between bonding and bridging social capital is that bridging capital is "outward-looking" because people become connected across different social groups rather than within similar social groups. An example might be a teenager who becomes friendly with someone in college and receives help navigating the college admissions process. Another example is a relationship developed between a synagogue and a mosque that leads to some sort of collaboration or supportive relationship between members of the two institutions. Here is another way to think about it: bonding social capital is good for "getting by," while bridging social capital is good for "getting ahead" (Putnam 2000).

The vertical dimension of social capital is referred to as linking social capital-the extent to which individuals build relationships with institutions and individuals who have relative power over them by providing access to resources, jobs, or services (Claridge 2004; Szreter and Woolcock 2004; Woolcock 2001). Linking social capital is also outward-looking but is different from bridging social capital because the power differences between partners are a conscious part of the relationship. While bridging social capital develops horizontal trust among unlike groups, linking social capital involves vertical relationships between actors with differential levels of power (Schneider 2006). This could include a client/social worker, employee/trade organization, or community member/rabbi. Linking social capital is the weakest relationship but often produces the most valuable outcomes, since linking provides access and connection to power structures and institutions. Linking social capital develops over time as actors across power relationships build trust with one another (Schneider 2006).

Hawkins and Maurer (2010) drew on these three forms of social capital to examine how 40 families utilized their social capital to survive, relocate, and rebuild their lives after Hurricane Katrina in New Orleans. The authors found that bonding social capital provided families with immediate support, but that bridging and linking social capital offered pathways to longer-term survival and wider neighborhood and community revitalization. Others have also documented that people are much more likely to survive weather-related disasters like hurricanes and heat waves when they know other people who will check on them and help them get to safety (Klinenberg 2015). In this study, we examine the roles that bonding, bridging, and linking social capital play in helping families through a pandemic.

\section{The Setting: Philadelphia}

For several reasons, Philadelphia is a useful location for our study. The COVID-19 pandemic is having an unprecedented impact on the Philadelphia region. Following the announcement of Philadelphia's first confirmed case on March 10, schools 
were closed on March 16 and a stay-at-home order began on March 23. The order imposed several public health restrictions on the city's residents designed to slow the spread of infections and prevent the crisis from overwhelming the city's healthcare capacity (City of Philadelphia Office of the Controller 2020a). The stay-athome order resulted in thousands of temporary business closures and the highest unemployment levels since the Great Depression. Between mid-March and the end of June 2020, more than 167,000 workers-over $20 \%$ of the city's total workforcefiled for unemployment, with the highest levels in industries that could not shift workers to telecommuting, such as health care, social assistance, and childcare (City of Philadelphia Office of the Controller 2020b). These industries are more likely to employ low-wage workers (making less than $\$ 40,000$ annually), meaning job losses have been the largest for the city's most vulnerable (City of Philadelphia Office of the Controller 2020c). Worker hours for those still employed decreased by more than $60 \%$ relative to pre-crisis levels, and school closures also forced parents from across the economic spectrum to take on the enormous responsibility of their children's education at home.

Some federal relief legislation was passed to mitigate the effects of the pandemic. For example, there were enhanced unemployment benefits for workers and forgivable loans for small businesses. These unemployment benefits and forgivable loans were made available to those who are not usually eligible for regular unemployment insurance benefits. This included business owners, self-employed workers, independent contractors, and those with a limited work history who were out of business or had significantly reduced their services as a direct result of the pandemic (U.S. Department of Labor 2020). Families whose children qualify for the National School Lunch Program or the School Breakfast Program also received about $\$ 370$ per child (\$5.70 for each day school was closed) on their EBT [electronic benefit transfer] card (Pennsylvania Department of Human Services 2020).

Yet federal relief tends to be insufficient for meeting the needs of people experiencing economic precarity, as they usually don't have any money to serve as a cushion, and government funds usually take a while to apply for and receive. Conversely, religious and ethnic organizations in Philadelphia tend to be less bureaucratic and more nimble, which means they can help people before they become housing- and food-insecure. In particular, the Greater Philadelphia area has a robust network of Jewish social service organizations that played an important role in providing economic resources and food to support Jews experiencing financial hardship during the pandemic. For example, the Jewish Federation of Greater Philadelphia committed to providing essential resources for the community during the crisis caused by COVID19 (Jewish Federation of Greater Philadelphia 2020). On March 17th, the Federation established an Emergency Response Fund, supported by gifts from the community, including matching grants from private foundations. The Jewish Federation Real Estate group also leveraged their funds for an additional Emergency Campaign, and facilitated matching grants for critical services. The Congregational Rabbis Emergency Fund provided aid to congregants and community members who needed financial assistance for food, rent/mortgage/utilities and/or medical expenses. Jewish Family \& Children's Service (JFCS) was able to provide two rounds of grants for basic needs such as food, rent, medical, mortgage or utility payments. The Jewish 
Relief Agency (JRA) was able to continue food distribution to more than 6000 clients monthly, and the Mitzvah Food Program was able to offset the cost of food and supplies for three months to those who had recently become food-insecure.

The Philadelphia Jewish community has one of the highest concentrations of lower-income Jews in the United States, and as a result was particularly hard hit by the pandemic. The Greater Philadelphia region has about 194,000 Jewish households, with about 445,000 people living in these households (Community Portrait 2020). About $10 \%$ of Jewish households in the Greater Philadelphia area live at or below the poverty line and are thus eligible for public benefits such as food stamps (Community Portrait 2020). ${ }^{3}$ About half of these households (including those with children) are food-insecure. At the same time, the Jewish community in Philadelphia is very diverse in terms of affiliation: $43 \%$ of Jewish households do not identify with any denomination, 26\% identify as Reform, 26\% as Conservative, $8 \%$ as Orthodox, 6\% as Reconstructionist, and 7\% as something else (Community Portrait 2020). In terms of engagement, about one-quarter of Jewish households belong to a synagogue (Community Portrait 2020). The variation in affiliation and engagement was important because we wanted to examine whether Jewish families with strong ties to other Jews and to Jewish institutions were more likely to access support from Jewish organizations.

\section{Data and Methods}

We recruited people in the Greater Philadelphia area ${ }^{4}$ to participate in virtual interviews with the lead author. ${ }^{5}$ Participants received a \$40 Amazon gift card for participating. We initially recruited participants by going through the social networks of the lead author, who grew up in Philadelphia. The author's contacts posted our recruitment ad on various parenting groups throughout the Philadelphia area and the ad was circulated on Facebook. We were able to recruit about half of our sample through these leads and through snowball sampling from these leads. To recruit more participants, we sought help from Jewish organizations, who circulated our ad on their own listservs. Because of this, it is likely that our sample is biased towards those who already receive support from Jewish social service organizations. In other words, we can make limited claims about the prevalence of social capital, since several participants had to have some social ties within the Jewish community to find out about the study in the first place.

Participants met the following criteria: (1) one parent identified as Jewish (culturally, ethnically, or religiously), (2) the parent had to have at least one child in K-12,

\footnotetext{
${ }^{3}$ Rates vary by county: in Philadelphia County, $20 \%$ of Jews live below the poverty line, compared with $7 \%$ in Montgomery County.

4 Including Philadelphia, Montgomery, Bucks, Chester, and Delaware counties.

5 This project was approved by the Stanford Institutional Review Board.
} 
and (3) the combined household income was $\$ 75,000 /$ year or less. ${ }^{6}$ We chose a cutoff of $\$ 75,000$ to capture people who were earning below the median Philadelphia area Jewish household income (Community Portrait 2020). Since the Greater Philadelphia area varies significantly in terms of median family household income among all families, we expected our participants' incomes would be above the median family income in Philadelphia County $(\$ 44,000)$ but below the median family income in neighboring Montgomery County $(\$ 126,000)$ (U.S. Census Bureau 2019). We focused on parents with school-age children because they were experiencing a unique challenge while sheltering in place - they had to continue working while also caring for their children (and potentially helping them with virtual schooling). We also expected that parents with financial setbacks might be especially worried about feeding their children. We were curious whether these parents were able to tap into their social capital as they managed their professional, domestic, and educational aspects of their families' lives.

Interviews occurred between August 16 and October 2, 2020. They ranged from 47 to $90 \mathrm{~min}$, with an average of approximately $70 \mathrm{~min}$. All interviews were conducted on Zoom and were recorded and transcribed. We developed a codebook to systematically tag interviews for key themes, and coding was done in Dedoose. After we completed all the interviews, we developed a survey to systematically capture information that emerged in the interviews, particularly around bonding social capital that was specific to the Jewish community. Based on common measures of social capital (Kikuchi and Coleman 2012; Yang 2007), we asked participants to indicate whether in the past two years they had donated to a Jewish organization, volunteered for a Jewish organization, were active in a Jewish organization (aside from a synagogue), or were active in or belonged to a synagogue, and how many of their five closest friends were Jewish. We also conducted a member check, where we sent our manuscript to all 36 parents and asked them to provide feedback (five parents sent feedback) (Creswell and Creswell 2017).

We interviewed 36 parents (one per household). We acknowledge that in some cases, such as parents' attitudes about their children's Jewish education, researchers ought to consider perspectives of both parents (Horwitz 2019). However, in this study, we expected parents to have similar accounts of their economic situation and thus interviewed only one parent (usually the mother). Although we only interviewed one parent, we asked that parent several questions about their spouse (if they were married). Throughout the paper, we sometimes refer to our sample as parents or families/households. The following is a description of our sample characteristics.

\footnotetext{
6 Two households earned more than $\$ 75,000$ : one household earned about $\$ 100,000$ before the pandemic, but it had fallen to $\$ 75,000$ by August 2020. The second household earned about $\$ 100,000$ and wasn't affected by COVID-19. They had misunderstood the eligibility requirements until we were well into the interview.
} 


\section{Income}

Families' incomes all fell below the median income in the Greater Philadelphia area, ranging from about $\$ 18,000$ to $\$ 75,000$. More than two-thirds of the families ( $n=25)$ we interviewed were receiving public assistance (such as food stamps) and/ or had children who qualified for free or reduced-price lunch (a common proxy of poverty). We consider these 25 families to be low-income, while the other 11 families were more like middle-class Americans (even though they fell below the median income of Philadelphia Jewish households). Most parents in low-income households worked in lower-wage jobs in industries that could not shift workers to telecommuting. About half of families $(54 \%)$ had at least one parent who was a K-12 or preschool teacher. Regardless of their actual income, almost all 36 families had very little financial cushion, with only $6 \%$ of families feeling they were "living comfortably"; $42 \%$ felt they could "meet their basic expenses with a little left over for extras," $39 \%$ felt like they were "just meeting their basic expenses," and $12 \%$ felt they "didn't have enough for basic expenses." Low-income parents included people like Emma, a single mother of one child who earned about $\$ 22,000$ as a daycare worker and had recently moved in with her parents (where her brother also lived with his son), and Orit, who had been staying home to care for her four young children while her husband worked as a therapist earning about \$20,000. Middle-class parents included Jeremy, a single parent who worked as truck driver earning about $\$ 60,000$ and was supporting one son, and Nancy, a single parent who worked as a professor earning about $\$ 75,000$ and was supporting two children.

Over one-quarter (28\%) of parents had experienced significant downward mobility in the past decade. Most were now single mothers whose former husbands had been the primary earners and the couple had decided that the woman would focus more on the children and less on her career. Then came an unexpected divorce or death that left these women with full-time childcare responsibilities, few job prospects, and even legal battles over child support. ${ }^{7}$ Most of these women went from being middle-upper class to pulling their children out of private schools and experiencing food and housing insecurity.

\section{Education}

Our sample was more highly educated than the average US low-wage worker. While only one-third of Americans earn a bachelor's degree, 78\% of parents in our sample had earned at least a BA and their spouse usually had as well. Several of the middleclass families had at least one parent with an MA, MD, JD, or PhD and had pursued careers in the education, nonprofit, or government sector.

\footnotetext{
7 In two cases, the women we interviewed were in the process of getting divorced because their husbands were abusive. Neither of these women had been receiving child support from their former husbands, and both had been trying to take their former husbands to court since early 2020 , but the process had completely stalled because courts were not taking cases as a result of COVID-19.
} 


\section{Family Structure}

Families had a range of 1-6 children under the age of 18 . The average number of children per family was 2 . At the time of the study, 14 families (39\%) were supporting only one child, while seven families (19\%) were supporting four or more children under 18. About half of our sample (44\%) were single parents, in most cases single mothers. Most of these parents had sole or primary custody of their children and were often fully responsible for supporting their child(ren) financially. Most single parents were divorced, though two single mothers had chosen to adopt their children.

\section{Geographic Location}

About half of the families (56\%) lived in Philadelphia County, with more than half of these families living in Northeast Philadelphia. Another 27\% lived in Montgomery County. The remaining 17\% lived in Delaware and Bucks counties.

\section{Religious Affiliation and Jewish Institutional Involvement}

In terms of religious diversity, just under half (44\%) of parents identified as Orthodox (which is about five times the percentage of Orthodox Jews in the Philadelphia area) or as part of Chabad (all of whom belonged to or regularly attended an Orthodox synagogue $)^{8}, 17 \%$ as Conservative (and had varied levels of synagogue involvement), and $22 \%$ as "just Jewish" (most of them were not active in a synagogue). The remaining five families were Reform or Reconstructionist, with varying levels of synagogue involvement. Of the 20 families with two married parents, $25 \%(n=5)$ had one non-Jewish parent, though all of them were raising their children Jewish. Sixty percent of households had at least one child in a full-time Jewish school, 55\% had donated to a Jewish organization in the past two years, $62 \%$ had volunteered in the past two years, and $72 \%$ had dense Jewish networks (at least three of their five closest friends were Jewish).

\section{Other Demographic Characteristics}

In terms of racial diversity, two households $(6 \%)$ had someone who identified as a person of color. In terms of national origin, $8 \%(n=3)$ of our participants were born outside the US. One was from Latin America and had immigrated within the past 10 years, and the other two were born in the former Soviet Union and had immigrated to the US as children. While some of our participants had lived in Israel for

\footnotetext{
8 We do not use "Chabad" and "Orthodox" synonymously because at least one of the parents we interviewed said they identified as "Chabad" but did not feel comfortable being called "Orthodox." We also do not use the term "ultra-Orthodox" because a few parents found the term offensive.
} 
some period of time, no one was born in Israel. We also interviewed two families who identified as gender queer.

\section{Findings}

\section{How COVID-19 Affected Employment}

About half (47\%) of families were in a worse financial situation because of COVID19. However, there was a significant difference between how the middle class fared compared to the low-income families. Low-income families were more than three times as likely to have financial setbacks after COVID-19 hit as middle-class families. This disparity is not surprising, given that many of the low-income families in our sample worked in industries that were most negatively impacted by COVID-19, and aligns with the broader national trend that the economic fallout from COVID-19 hit lower-income Americans the hardest (Pew Research Center 2020).

About half of the families who fared worse because of COVID-19 received unemployment benefits, ${ }^{9}$ but several were unable to offset their lost income that way. This included parents who worked side gigs earning cash. For example, Devorah, a teacher, earns a few extra thousand dollars cooking and baking for others, which she could not do during COVID-19. Zalman also could not recoup the five weeks of pay he lost when he and his wife both contracted COVID-19. On top of the economic stress, they had to care for their children while being sick. This was especially hard as Zalman's wife has mental health struggles and was worried that the stress of being sick and losing income would spiral them into a mental health crisis and land her in the hospital (which had happened before).

As we were writing this article in fall 2020, millions of Americans were experiencing long-term economic setbacks because of unemployment or reduced employment that is likely to last beyond the pandemic unemployment benefit period (Liu 2020; Stettner and Pancotti 2020). This means that people who are already living paycheck to paycheck are facing long-term economic uncertainty. We found this trend in our sample as well. For example, prior to COVID-19, Rivka worked two jobs: part-time in medical billing and also as a consultant for people with disabilities. After shelter-in-place went into effect, she lost one job and her hours were cut in half at the other. She is not sure whether her jobs or hours will return. Her husband, who worked as a financial advisor for a large financial services firm and was largely dependent on commission, was also unable to maintain his income. His business involves meeting people, which was always done in person. Now, the company is trying to reconfigure their business model to conduct virtual financial planning. In

\footnotetext{
9 Through the COVID-19 employment assistance program, people were eligible to receive an additional $\$ 600$ weekly benefit between April 4 and July 25, 2020. Even those who wouldn't have generally qualified for unemployment (e.g., they were an independent contractor or a gig economy worker) were eligible for up to 39 weeks of unemployment benefits through the Pandemic Unemployment Assistance program, which expired on December 26, 2020 (https://www.uc.pa.gov/COVID-19/CARES-Act/Pages/ FPUC-FAQs.aspx).
} 
the meantime, her husband hasn't been able to find people who are interested in his services.

A few families had an economic setback a few months after the pandemic hit. In August 2020, one parent working as an educator learned that he would receive a $10 \%$ pay cut for the upcoming school year. His wife's income may also decrease in the upcoming months. She is a part-time fitness instructor and has been offering virtual classes, but is worried that her clients will experience Zoom fatigue and not continue their sessions. This is not money they can recoup through unemployment benefits.

\section{How COVID-19 Affected Finances}

COVID-19 created a palpable feeling of uncertainty and instability for respondents who don't have much cushion. While most Americans are experiencing uncertainty from COVID-19, those living paycheck to paycheck are more adversely affected by the inability to plan, since they have so little room for error. Families who live with financial uncertainty constantly worry about the unexpected: Will an appliance break? Will my electricity get shut off? Will I have enough food and diapers for my kids? What if the car breaks? Several people told us they have had bad experiences using credit cards in the past and accrued debt, and now only try to spend money that they actually have.

At the same time, government benefits, while very helpful, came with two downsides for families who carefully plan their budgets. First, it took a while for the government to pass the relief package that yielded unemployment benefits, so families couldn't account for such assistance in their budgets. Second, unemployment checks often took a long time to arrive, which resulted in a lot of anxiety for those living paycheck to paycheck. To receive unemployment checks, they had to complete an application and then wait at least two to four weeks. Some families were not immediately approved to receive unemployment, appealed, and then received their unemployment in a lump sum a few months later.

The financial anxiety that COVID-19 brought on was deeply pronounced for single parents with young children like Cindy, a single mother with a special-needs child. Cindy had been struggling financially ever since her husband died eight years earlier, when she and her child experienced significant downward mobility: "I went from being almost upper middle class to floundering very quickly once he died." She was a writer whose career has been significantly hindered by the shift to online media. These days, Cindy relies on her son's disability benefits and she sells items that she, her neighbors, and friends don't use (e.g., through Amazon, eBay, and at flea markets). COVID-19 has made things especially difficult because Cindy has an even harder time finding work, and the work that is available pays very little. Since her child is now doing virtual school, Cindy has to stay home to care for him, which further limits her employment opportunities.

Avigail, also a single mother with sole custody, was working as a therapist at a hospital before COVID-19. She had intentionally worked part-time to allow her former husband to focus on his career, but had recently gotten divorced. When 
shelter-in-place went into effect, she had full custody of her two young children, who were unable to go to school. Because of safety and financial constraints, she could not hire childcare help. While she was able to run some of her therapy groups online, her hours were cut in half. As of August it was not clear whether she would have income in the upcoming year. If her children cannot return to school, she cannot return to work. As she says, "Literally every piece is moving. I don't know how to plan because of COVID."

In about $40 \%$ of the families in our sample, at least one parent worked as an educator. Educators felt an extremely high sense of uncertainty because even as late as August some didn't know whether they would be employed in the upcoming school year. For example, as of mid-August, Tal, a preschool teacher already struggling to make ends meet given their $\$ 30,000$ salary, was still not sure whether the preschool would reopen in the fall for in-person learning. If it does not, Tal will not receive any income. Their spouse, who recently completed a $\mathrm{PhD}$, is also unlikely to find steady employment given that most universities have a hiring freeze. Jobs outside academia are very hard to come by. "It's a very tenuous situation," Tal says. Tal's spouse hopes to do some consulting work, but if Tal is not able to resume their work at the preschool, they will lose their benefits and steady (albeit small) income.

\section{Examples of Social Capital}

Bonding social capital within the Jewish community was most consistently evident among Jewish parents who were actively involved in Jewish organizations. In many (but not all) cases, these parents were Orthodox. People who are part of Orthodox Jewish communities have high levels of network closure, which promotes bonding and linking social capital. They live near each other, send their children to the same schools, regularly attend the same synagogues, shop at the same kosher supermarkets, and have similar and consistent norms and expectations for how they and their children behave. Network closure promotes high levels of trust and makes information sharing easier. In tight-knit Orthodox communities, members pitch in even when they are busy or stressed. The sense of reciprocity is what generates bonding social capital, or what Benor (2013) refers to as "reciprocal altruism."

For example, Miriam, a study participant who lives in an Orthodox neighborhood, described how her husband recently stopped by his rabbi's house and gave the rabbi \$50 that he and Miriam had left over that week so that the rabbi could distribute it to other people in the community who were struggling. By donating leftover funds to the rabbi, Miriam and her family partake in a collective effort to support the community, all of which serves to lubricate the flow of social capital. Zalman's attitude towards giving back to his community captures reciprocal altruism perfectly: "I don't want to feel like I'm leeching off people... I want to be a positive contributor... we really don't have a lot to give [financially] but I volunteer to be on security [for the shul]... I always volunteer for that, even though that messes up your whole davening." Similarly, Tanya and her husband-parents of six children and experiencing high levels of financial stress-still take a very active role in their community: 
I'm a big part of the school... I am active in a lot of different community organizations, my husband runs a father-son learning group... I do meals for people that just moved in, or people that have a baby or people that are going through something, so I run a mitzvah meal program. I am also part of chevra kadisha and I'm part of fundraising for the Mikvah Association here. My husband's on the board at the shul. We're ingrained in this community. We do a lot. We're invested in it emotionally, physically. We believe in it.

Shared norms play a big role in facilitating bonding capital, which helps explain why social capital flows more readily through Orthodox neighborhoods. A few Orthodox families living in Northeast Philadelphia (which has a robust Orthodox Jewish community) made a point of saying that they live in modest homes because such homes reflect the norms of their particular Orthodox community. Moving into an ostentatious home or buying a flashy car would not be aligned with how other members of this community live and would potentially create social rifts. In this community, embracing an economically modest lifestyle translates to a lower level of stigma around financial struggles in religious communities, because a fair number of families experience economic insecurity (especially compared to Jews who belong to Reform or Conservative synagogues that are more affluent).

Social class divides appear to impede the flow of social capital between Jews. For example, Orthodox Jews in our study who lived on the Main Line (which is an affluent neighborhood in Montgomery County) reported feeling insecure about experiencing financial struggle because the differences between the "haves" and the "have nots" were more apparent. When social class differences surface, they seem to create tension that stymies the flow of capital. A few of the parents in our study described having cross-class relationships with more affluent Jews, and these relationships did not seem to be marked by trust and reciprocity. This is precisely what happened to Jennifer, who has a few close Jewish friends from college and through a Birthright trip to Israel. Although Jennifer's friends are Jewish, they are from different social class backgrounds:

It is two different worlds. My one friend whose children are the same age as mine-I felt like we had children and would hang out, but they just bought like a $\$ 600,000$ house. My husband doesn't feel like when we go there that we fit in... I don't know if they're part of a congregation, but I wouldn't feel comfortable [attending]... they probably all drive Lexuses or BMWs and live in $\$ 600,000$ houses. I live in a row home... I am a Jew who coupons.

Jennifer doesn't share her friends' norms, and trust doesn't flow through these networks like it did in communities where everyone had similar social class positions. Emma, another young Jewish mother, also described how social class differences created a barrier to her participation in a Jewish community. Emma used to belong to a synagogue when she was growing up, but always felt a divide between herself and her wealthier peers. When her daughter was born, she decided to try to re-engage with the same synagogue, but the class divide was still a barrier. She continued to try to engage with the community by holding her daughter's baby-naming 
at the synagogue and also attending one Shabbat service geared towards children. However, she felt completely unwelcomed and vowed never to return again.

In cases like Jennifer and Emma, cross-class relationships between Jews appear to function as bridging social capital rather than as bonding social capital. Notably, the flow of social capital is not necessarily a reflection of religious affiliation or religious involvement. While Orthodox Jews tend to have more access to social capital, we found that non-Orthodox Jews had access to social capital, especially if they were active in their synagogues. We also interviewed people who attended Orthodox synagogues to pray but had little access to social capital because they didn't participate in the social life of the synagogue.

Linking social capital flows most readily when bonding capital is strong-this helps people "be in the know." Usually, this means that people need to be highly involved in the community so that there is a give and take component that engenders trusting relationships. As Portes (2000) puts it: "Social capital of any significance can seldom be acquired without the investment of some material resources and the possession of some cultural knowledge, enabling the individual to establish relations with others" $(2000,2)$. Plainly put, receiving Jewish books in the mail through PJ Library (as Jennifer did) will not connect people into the kinds of networks that facilitate social capital; developing networks of trust and reciprocity usually requires a more active role in Jewish institutions (though they don't have to be synagogues). People are unlikely to accrue much social capital if all they do is come to synagogue, pray, and leave without having any social interaction.

Parents with stronger levels of bonding social capital appear to have stronger linking social capital in the Jewish community. Linking social capital was most abundant among Jews who had relationships with rabbis-most commonly Orthodox Jews. Rabbis have power and authority and can help secure resources and connect people with those resources. Linking social capital-which flows vertically across people or institutions at different levels of societal power hierarchy-is generated when community members connect with those who have authority and influence. For Jews, this is often a rabbi. A person who is struggling may not feel comfortable contacting a rabbi themselves, but if they have bonding social capital, someone may suggest that they seek help from a rabbi. This is precisely what happened to Orit when a member of her family was experiencing a mental health struggle. She didn't know what to do and reached out to a friend. Her friend urged Orit to contact their rabbi, who was able to provide emotional and financial support to get her family through the crisis. As Orit recounts:

We had a crisis about a year and a half ago. A mental health crisis. And we did need a little bit of support during that time. My friend said, 'Listen, I'm calling the Rav [rabbi]. You're okay with that?" I'm like, "Yeah, sure.” I probably would not have made a phone call. But the Rav was like "I'm sorry I didn't know about this sooner. What do you need?"

Jewish family members also link parents through bonding social capital to Jewish community organizations. When Linda experienced unexpected and significant downward mobility, her mother suggested that she contact JEVS Career Strategies, a Jewish organization she was familiar with because her own mother had volunteered 
there. Linda used to work as a management consultant, traveling all over the world and earning over $\$ 100,000$. Eventually, she became disillusioned with certain practices and philosophies in her company and quit, but after the Great Recession in 2008 she had a very difficult time finding a new job. Her husband also got sick and experienced a significant financial setback. They had to sell their house and rent an apartment in the area so that they could keep their son in the school district. The downward mobility has been very difficult, not just financially but socially and emotionally as well. As Linda recounted, "We had our own house and a whole regular world - a little more of what you would expect of a Jewish family... we sold our house and I used up my entire 401(k)... Now we live in a beat-up kind of place, [but] I wanted to keep our son in the school district and there aren't many rentals available." Linda was active in a Reconstructionist synagogue, which helped her feel more comfortable about the idea of accepting help from a Jewish institution: "They are wonderful," Linda told us. "They really worked with me to get a job and really work on myself so I could get hired." JEVS also helped Linda pay her rent while she was trying to get her family back on their feet. In sum, parents with higher levels of bonding social capital in the Jewish community also experienced more linking social capital in the Jewish community.

\section{The Role of Social Capital During the Pandemic}

Social capital did not play the same role in a pandemic as it does in weather-related disasters like hurricanes and heatwaves. Almost everyone in our study took the shelter-in-place orders very seriously and abstained from seeing others (including family members outside their house). Yet social capital tends to be valuable precisely because people physically help each other. During Hurricane Katrina, people in New Orleans waded through rising water to save their neighbors; in Chicago during the most recent heat wave, people checked in on acquaintances who lived alone and didn't have air conditioning. But the aspect of bonding capital that makes it so valuable - the tangible physical assistance it can yield - is not as helpful in a pandemic that requires physical distancing. For example, Zalman and his wife, who live in an Orthodox Jewish neighborhood, could not tap into their social capital to get childcare help when both of them contracted COVID. The inability to convert social capital into childcare was especially difficult for single parents who had to care for young children during shelter-in-place and couldn't be productive in their jobs even if they were able to work remotely. It also impacted their mental health since they had little opportunity to rest.

In the absence of physical help, the main way parents took advantage of bonding social capital was to ask their family members for financial help. Most parents were able to get some help from their parents, before and during COVID-19. For example, Elisheva's mother sent her stimulus check. Linda's in-laws provided them $\$ 500$ monthly, which helped when her husband had to stop driving for Lyft/Uber because he was immunocompromised. Zalman's father bought his children tablets to keep them occupied while the parents recovered from COVID. A few parents had some inheritance they could tap into. 
Certain types of information exchange-one of the manifestations of bonding capital—proved to be generally not beneficial in a pandemic. For example, several parents learned about online activities (Jewish and non-Jewish) they could do with their children through family members and friends, but almost none of the parents took up the activities. As Ruth recalled:

I muted my family's WhatsApp chat and I haven’t unmuted it since. Everyone just started putting things up and they've all been spamming me the whole time. I haven't really used any of it, not because I don't want to-just because I never had time. Once, I sat down to look at it, and I was just like, "I don't really need this." We've been fine up until now. No need to change it now.

It is possible that other, more beneficial types of information were exchanged, but we did not hear about it during our interviews.

Instead, linking social capital appeared to be the most valuable form of social capital during the pandemic because it connected parents to material resources. However, Jewish parents developed linking social capital through having accrued bonding social capital. It was precisely through their close-knit ties in the Jewish community that parents were able to connect to people and institutions of power that had the resources they needed. By leveraging linking social capital, parents received support from any number of Jewish institutions. Tellingly, all of the parents in our sample who received help during COVID-19 were already working with these organizations, so their contacts within those organizations already knew to reach out to them when the pandemic hit.

Cindy, a single mother with a special-needs child, is one of the people who received supermarket gift cards during the pandemic. Cindy already had linking social capital via a relationship with a case worker at JFCS. But Cindy's initial connection to the social worker came through a friend who works at the synagogue preschool (i.e., bonding capital): "When things got tough, my friend was the one who told me about the food bank. And, and I said, 'I don't know, I'm a little embarrassed.' And she said, 'I'm going to enroll you, you don't have to do anything."' Now, Cindy's social worker provides her invaluable support: "She's always letting me know about opportunities, like getting $\$ 500$ back on my property taxes and helping me fill out the forms to make it happen." At one point, when Cindy had $\$ 600$ of unpaid bills, she reached out to one of the Jewish organizations who paid it off on her behalf. A few months ago, her oven broke and a Jewish organization covered most of the cost of a new oven. Receiving such help takes a lot of forms and time, but Cindy is happy to have the help. She is using her neighbor's oven to cook dinner for Rosh Hashanah but hopes to have an oven by Thanksgiving.

During COVID-19, support from Jewish organizations was significantly amplified for people like Cindy in a variety of ways. Jewish organizations like the JRA started delivering food to clients who could no longer go to a food bank and sent families gift cards to supermarkets. Rabbis were able to support congregants and community members using discretionary funds. Several people told us about receiving phone calls from their rabbi asking if they needed help, and then receiving an envelope with cash. Ruth, a mother of four children, described how helpful it has been to receive support from Jewish organizations as well as her rabbi: 
They've [the Jewish Organizations] been very helpful with all these additional things, not just for the pandemic... especially the JFCS. If I need to speak to someone, I can just call or text message and she's there helping me... I've asked for help finding a therapist for my children and she actually helped me through the whole SNAP [Supplemental Nutrition Assistance Program] application... Then the rabbi got some money to give out to the families in need. He actually sent me some money, so that's been helpful. My kids' school actually called me a few months ago and they said that there's somebody who bought like $\$ 10,000$ worth of gift cards to the House of Kosher supermarket and he's giving [them] out to all the different schools to give out to parents. So she mailed me $\$ 400$ in gift cards. It was actually nice getting all these things because food stamps only cover certain things. So when my daughter was not potty-trained, I needed to buy diapers, I just was able to go there and use the gift card for the diapers and stuff.

Rabbis were an especially important source of support during COVID-19 because they received discretionary funds through the Federation to help their congregants and community members. Families who had a relationship with their rabbi were much more likely to report that they received discretionary funds. As Elisheva, a single Orthodox mother earning $\$ 32,000$ a year, recalled, “There were a number of pieces of money floating around [in the months following shelter-in-place]... The rabbi kept calling up, 'Do you want $\$ 1000$ ?' he said. 'You don't have to pay it back." Zalman described how helpful his rabbi has been in supporting him through rough patches: "The rabbi has a discretionary fund... when we first met him [a few years back], we explained our financial situation and he would help us out. I was in the hospital once, and he said, 'If you need money, let me know. I can help you out.' Even $\$ 100$ helped a lot." On another occasion, the rabbi helped the family with a large and unexpected car repair bill. Those who received help were already hooked into the Jewish communal support infrastructure, and even those who didn't have financial setbacks knew that help was available. For example, ever since Orit's rabbi helped her family through a health struggle, he checks in on them: "Now he calls me every now and then and says, "How are you guys doing? With the pandemic, if you ever need any money, let me know." They haven't needed any help during the pandemic, but they know they can turn to him for help if they run into trouble.

Low-income families who lacked bonding social capital did not have linking social capital to help during the pandemic. Consequently, they didn't receive any help from Jewish organizations during the pandemic. Emma earned only $\$ 11.50$ an hour as a preschool teacher and received diapers for her daughter from a Mitzvah circle, but she only found out about the organization because a Catholic charity told her about it. She found out about the Catholic charity through the WIC [Special Supplemental Nutrition Program for Women, Infants, and Children] office, which did not appear to advertise or even know about Jewish charities. Jennifer, whose spouse has a disability and who is struggling to make ends meet, also did not know that Jewish social service organizations were available for financial and mental health support. Jennifer and Emma were not complete 
strangers to the Jewish world, but they lacked strong bonding capital in the Jewish community because they were not affluent like the Jewish communities they tried to enter. Thus, when rabbis received discretionary funds to help struggling families through the pandemic, people with low levels of bonding social capital like Emma and Jennifer were literally not linked to these sources of support. This was a stark contrast to families who had rabbis who knew about their financial hardships and reached out to them when resources were available.

Low-income families who did have access to linking social capital saw it flow through bonding social capital. In the absence of a relationship with a rabbi, almost all the people in our sample who received support from Jewish social service organizations learned about them through someone else-family members, friends, and neighbors - that they were bonded to. Only five people found out about Jewish social service organizations on the internet, compared with 16 who learned about them through friends, family, neighbors, or a rabbi. Indeed, more than a few parents we interviewed pointed out that you have to be "in the know" to find resources in the Jewish community. Kari, who lives in South Philadelphia and moved there from Minnesota, feels that it's harder to get connected to resources in the Philadelphia area than in other cities she has lived:

I feel like in Philly, if you are in the know, then you know, but if you're not, then it's almost impossible to break into those networks, especially if you're outside of their kind of catchment which is like not South Philly... it really feels like there hasn't been any outreach from the Federation and there hasn't been any outreach from the JRA or any of the resources around here.

It is important to note that not all accumulated bonding social capital translates into linking social capital. For example, Jennifer, who had gone on Birthright in college and participated in the Meor program in college, could not turn to these organizations for financial help or mental health support for her spouse. Nor do private acts of religiosity lubricate the flow of social capital. Rather, people develop relational ties by doing something with and for a social group. For example, Nancy is not actively involved in a synagogue, but volunteers for other Jewish organizations, donates to Jewish organizations, and sends her children to a Jewish school. Perhaps not surprisingly, four of her closest friends are Jewish. Recently, when she had to unexpectedly leave her home due to an unsafe living situation, one of her friends she met through her children's Jewish school contacted JFCS on her behalf, who then helped her pay the security deposit and first month's rent on her new home. This is the epitome of bonding capital being converted to linking social capital, which is what Jewish parents need to readily access material resources.

\section{Social Distancing: A Threat to Social Capital?}

Social distancing simultaneously strengthened and disrupted flows of social capital. Jewish parents reported that staying home together for a long period of time strengthened ties with immediate family members. For those who were particularly religious, they remarked how much they enjoyed the additional time with their 
children. This was especially true for Batya, a single mom whose relationship with her son had been rocky after his parents divorced: "Secretly I was very, very happy to be home with my son. You know, we spent a lot of time together... it actually helped to repair what was a difficult relationship... It did a lot for us." Elisheva, also a single mom, echoed a similar sentiment:

You know, it was actually really great. My [teenage] son was home. It was a time of real togetherness-we had this very sweet time. He learned to cook... [now] he's doing more cooking than I am, which for a single parent is really helpful. He is very helpful around the house. And he'll surprise me by doing the dishes sometimes. He's very aware of me being a single parent and me working.

But while necessary to prevent the spread of COVID-19, social distancing unsurprisingly threatens the type of social capital that is generated outside the immediate household. After all, social interaction is the lubricant of social capital. For most people, Jewish engagement revolves around the social sphere and not just the religious sphere. The social dimension of Jewish life-not the religious dimension-was what people missed during the pandemic. In fact, most parents, including those who were Orthodox, were not especially bothered by having to shift their religious life to the private sphere and were not especially eager to return to shul. But the social dimension was a more difficult adjustment. Dalia, an Orthodox mother who usually spends Shabbat with community members, reflected this attitude when she remarked how "it was definitely weird not having the synagogue, not being able to celebrate holidays like we normally would. We normally enjoy having company on the holidays, even on Saturdays, so that was an adjustment." Yael, who is involved in kiruv (Orthodox Jewish outreach to non-observant Jews), found it especially hard. For her, the religious and social are so connected and central to her life that the absence of them threatens her mental well-being: "It's really hard because the religious and social for us are so deeply intertwined... it's not just about spirituality, but it's about mental health. At this point, even if you're not a super spiritual person, like, your religious life is your social life." For a few families who generally spend Shabbat lunch with others and who usually go away for Passover, having to prepare their home for Passover and cook Shabbat lunches was also an unexpected financial burden.

Social distancing also threatens social capital by limiting people's involvement with communal organizations. Social distancing erodes the reciprocal nature of social capital. As we have argued, parents who were able to access resources from Jewish organizations were often those who contributed in some capacity to the system prior to COVID. Again, reciprocity is like a lubricator that enables social capital to flow more fluidly through networks. But social distancing can threaten reciprocity by limiting people's in-person acts of generosity. While individuals can still contribute money, there is little opportunity to actually give of their time to such organizations and join in communal efforts. For example, when Miriam's husband stopped by his rabbi's house to give him their leftover $\$ 50$, he altered his usual routine by visiting the rabbi before going to the market where he would be exposed to more people. Because of social distancing guidelines, his 
interaction with the rabbi was more brief than usual. If human interactions are stymied for long periods of time, social capital can break down. The pandemic also put on hold the other communal activities of the synagogue that Miriam's husband would have ordinarily participated in. It is hard to be involved in the community and keep the channels of volunteerism open when people need to maintain distance. Parents are also limited on time since they are constantly caring for their children. As Rivka said:

I don't have room in my brain to even think about involvement in the community. Someone who just had a baby asked if I could help them cook meals and I said, "I can make you peanut butter and jelly sandwiches, but nothing more." So I think any type of community or contribution at this point is way too much on my plate.

COVID-19 has created a situation in which people are able to convert their bonding social capital into linking social capital. But bonding social capital requires people not just to receive but also to give back. During the pandemic, it's operating in just one direction. If this goes on for a long time, it could threaten social capital, which is predicated on reciprocity. As Tanya remarks, her family's involvement in the Jewish community has come to a standstill:

I mean pretty much everything stopped. It was hard and weird... we couldn't fundraise for all the organizations that we were a part of because nobody had any funds. There were no funds available. Nobody had money. Everybody needed to have things earmarked for specific people or for their own families. And so that stopped.

\section{Discussion}

In this study, we examined how lower-income Jewish households in the Greater Philadelphia area fared in the five months following the start of COVID-19. We interviewed 36 parents who self-identified as Jewish, had at least one school-age child, and had a household income of $\$ 75,000$ or less. We looked at how different forms of social capital helped parents weather the economic hardship brought on by COVID-19.

Social capital is not developed through private acts like prayer but through social acts like service, and is therefore threatened in a pandemic when individuals are forced to shelter in place. Although bonding social capital did not help people with things like childcare or food preparation, it did help by facilitating linking social capital, which provided low-income parents material resources.

The lens of social capital helps us see how low-income Jewish parents could leverage their social relationships in the Jewish community to access valuable material resources. This study suggests that involvement in some Jewish organizations, especially synagogues, can yield significant dividends in unexpected ways. Specifically, people who were involved in synagogues were more likely to have confided in their rabbi that they had financial struggles, which meant that rabbis knew they 
might benefit from COVID relief funds. Ironically, when people feel financially constrained, synagogue membership — which typically involves mandatory dues-is often one of the first things they cut from their budget. While seemingly counterintuitive, economic hardship may be the best time to maintain synagogue affiliation, since synagogues can function as a system of economic and social support. Rather than dragging them further into debt, synagogues appear to actually help get people through a hard time. However, we also noticed that ties to different denominations yielded different material resources. Ties to Orthodox synagogues were most likely to result in financial support, whereas the few families active in their Reconstructionist synagogue did not receive discretionary funds. While we do not know why, it is possible that the rabbi from the Reconstructionist synagogue was not connected to the Jewish Federation and did not have discretionary funds to distribute.

We extend prior research by applying the theoretical concept of social capital to understand how social ties helped low-income parents during a pandemic. We have long known that social networks play an important role in sustaining Jewish communities (Benor 2013; Kadushin and Kotler-Berkowitz 2006; Wolfson 2013). However, the concept of social capital—especially the delineation between bonding, bridging, and linking social capital—gives us a different way to understand the power and limitations of Jewish parents' social networks in the specific context of a pandemic. Only a few studies have applied the concept of social capital to study Jews (Berger and Gainer 2002; Schlesinger, 2003), and we suggest that future research continue to use social capital as a theoretical lens to examine American Jews. We also extend prior research by focusing on low- and moderate-income Jews, to whom scholars have paid remarkably little attention. Social class plays a key role in shaping how people see themselves and how they relate to others (Fiske and Markus 2012). We suggest that future research pay close attention to how class lines might influence Jews' beliefs and behaviors.

Acknowledgements We are grateful to the 36 parents who candidly shared stories of their economic hardships, and to those who helped us recruit participants for this study. We also thank Laurence KotlerBerkowitz, Daniela Weiner, Jon Ball, Rafa Kern, Caitlin Brust, Jeremiah Lockwood, Matt Boxer, Landon Schnabel, Gila Silverman, Katie Soloway, Allen Glicksman, Talia Kaplan, David Kaplan, and Kelly Romirowsky for their feedback on the study design and paper drafts.

Funding This project was funded by Stuart and Suzanne Grant Center for the American Jewish Experience at Tulane University and the Jack, Joseph and Morton Mandel Center for Studies in Jewish Education, Brandeis University.

Data Availability Data may be available upon request; please contact ihorwitz@stanford.edu.

\section{Declarations}

Conflict of interest The authors declare that they have no conflict of interest.

Ethical approval This study was approved by the Stanford Institutional Review Board (IRB-57212). 


\section{References}

Benor, Sarah. 2013. Multiplex networks: The ties that bind. Shma, 7-8.

Berger, I., and Brenda Gainer. 2002. Jewish identity, social capital and giving. In NA: Advances in consumer research, vol. 29, ed. Susan M. Broniarczyk and Kent Nakamoto, 408-413. Association for Consumer Research: Valdosta.

Bourdieu, Pierre. 1986. The forms of capital. (1986). Cultural theory: An anthology 1: 81-93.

Cain, Daphne S., and Juan Barthelemy. 2008. Tangible and spiritual relief after the storm: The religious community responds to Katrina. Journal of Social Service Research 34(3): 29-42.

City of Philadelphia Office of the Controller. 2020a. Estimates of the impact of COVID-19 on the City of Philadelphia's tax revenues, April 2020. https://3og1cv1uvq3u3skase2jhb69-wpengine.netdna-ss1. com/wp-content/uploads/2020/04/controllers_office_fiscal_impact_COVID.pdf.

City of Philadelphia Office of the Controller. 2020b. Impacts of COVID-19 across Philadelphia's neighborhoods Part 1: The scale of the small business crisis. https://controller.phila.gov/wp-content/ uploads/2020/06/small-biz-series-part-1.pdf.

City of Philadelphia Office of the Controller. 2020c. Impacts of COVID-19 across Philadelphia's neighborhoods Part 2: Impacts on residents. https://controller.phila.gov/wp-content/uploads/2020/06/ small-biz-series-part-2.pdf.

Claridge, T. 2004. Social capital and natural resource management: An important role for social capital? Unpublished Thesis, University of Queensland, Brisbane, Australia.

Coleman, J. (1988). Social capital in the creation of human capital. American Journal of Sociology 94: 95-120.

Community Portrait 2020. 2020. Community portrait: A 2019 Jewish population study of greater Philadelphia. https://static1.squarespace.com/static/5b21656a4611a0d4e033d588/t/5e4a9cc8ac72271 63882d376/1581948109342/2019+Community+Portrait+-+Final+Report.pdf.

Creswell, J. W., \& Creswell, J. D. 2017. Research design: Qualitative, quantitative, and mixed methods approaches. Sage publications.

Fiske, Susan T., and Hazel Rose Markus, eds. 2012. Facing social class: How societal rank influences interaction, 1st ed. New York: Russell Sage Foundation.

Hawkins, Robert L., and Katherine Maurer. 2010. Bonding, bridging and linking: How social capital operated in New Orleans following Hurricane Katrina. British Journal of Social Work 40(6): 1777-1793.

Holcombe, Emily. 2010. Understanding community-based disaster response: Houston's religious congregations and Hurricane Katrina relief efforts. In The sociology of Katrina: Perspectives on a modern catastrophe, ed. D.L. Brunsma, 107-119. Lanham: Rowman \& Littlefield.

Horwitz, Ilana M. 2019. Foregrounding the family: An ethnography of how families make decisions about Hebrew school. Contemporary Jewry 1-18.

Jewish Federation of Greater Philadelphia. 2020COVID-19 Emergency relief efforts. https://jewishphilly. org/COVID-19-emergency-fund-grants/. Accessed 15 September 2020.

Kadushin, Charles, and Laurence Kotler-Berkowitz. 2006. Informal social networks and formal organizational memberships among American Jews: Findings from the National Jewish Population Survey 2000-01. Sociology of Religion 67(4): 465-485.

Kikuchi, Mami, and Cynthia Lou Coleman. 2012. Explicating and measuring aocial relationships in social capital research. Communication Theory 22(2): 187-203.

Klinenberg, Eric. 2015. Heat wave: A social autopsy of disaster in Chicago. University of Chicago Press.

Liu, Jennifer. 2020. Nearly half of people collecting unemployment benefits may not qualify for aid in 2021. C NBC. Retrieved March 21, 2021. https://www.cnbc.com/2020/09/03/nearly-halfof-workerson-unemployment-could-lose-benefits-end-of-year.html.

Pennsylvania Department of Human Services. 2020. Pandemic electronic benefits transfer (P-EBT) supplemental payments. https://www.dhs.pa.gov/providers/Providers/Pages/Coronavirus-PandemicEBT.aspx. Accessed 30 September 2020.

Pew Research Center, April. 2020. About half of lower-income Americans report household job or wage loss due to COVID-19. https://www.pewsocialtrends.org/2020/04/21/about-half-of-lower-incomeamericans-report-household-job-or-wage-loss-due-to-COVID-19/.

Poortinga, Wouter. 2012. Community resilience and health: The role of bonding, bridging, and linking aspects of social capital. Health and Place 18(2): 286-295. 
Portes, Alejandro. 1998. Social capital: Its origins and applications in modern sociology. Annual Review of Sociology 24(1): 1-24.

Portes, Alejandro. 2000. The two meanings of social capital URL: http://www.Jstor.org/Stable/3070334 Accessed: 13-04-2016 11: 27 UTC The Two Meanings of Social Capital. 15(1):1-12.

Putnam, Robert D. 2000. Bowling alone: America's declining social capital. in Lane Crothers and Charles Lockhart (eds), Culture and politics: A reader. Springer. pp. 223-34.

Rivera, Jason David, and Ashley E. Nickels. 2014. Social capital, community resilience, and faith-based organizations in disaster recovery: A case study of Mary Queen of Vietnam Catholic Church. Risk, hazards \& crisis in public policy 5(2): 178-211.

Schlesinger, E. 2003. Creating community and accumulating social capital: Jews associating with other Jews in Manchester. Institute for Jewish Policy Research 2(2): 1-29.

Schneider, Jo Anne. Social capital and welfare reform: Organizations, congregations, and communities. Columbia University Press, 2006.

Sheikhi, Rahim Ali, Hesam Seyedin, Ghader Qanizadeh, and Katayoun Jahangiri. 2020. Role of religious institutions in disaster risk management: A systematic review. Disaster medicine and public health preparedness $1-16$.

Stettner, Andrew, and Elizabeth Pancotti. 2020. 12 Million workers facing jobless benefit cliff on december 26. The Century Foundation. Retrieved March 21, 2021. https://tcf.org/content/report/12-milli on-workers-facing-jobless-benefit-cliff-december-26/.

Szreter, Simon, and Michael Woolcock. 2004. Health by association? Social capital, social theory, and the political economy of public health. International Journal of Epidemiology 33(4): 650-667.

U.S. Census Bureau. 2019. The 2019 American Community Survey, Table S1903. https://data.census. gov/cedsci/table?q=S1903\&tid=ACSST1Y2019.S1903.

U.S. Department of Labor. 2020. Unemployment insurance relief during COVID-19 outbreak. https:// www.dol.gov/coronavirus/unemployment-insurance. Accessed 30 September 2020.

Wolfson, Ron. 2013. Relational Judaism: Using the power of relationships to transform the Jewish community. Jewish Lights Publishing.

Woolcock, Michael. 2001. The place of social capital in understanding social and economic outcomes. Canadian Journal of Policy Research 2(1): 1-35.

Yang, Keming. 2007. Individual social capital and Its measurement in social surveys. Survey Research Methods 1(1): 19-27.

Publisher's Note Springer Nature remains neutral with regard to jurisdictional claims in published maps and institutional affiliations.

Dr. Ilana M. Horwitz is an Assistant Professor and Fields-Rayant Chair of Contemporary Jewish Life at Tulane University, and the Education Fellow at the Stanford Center on Longevity. Sasha Lascar is an undergraduate student at Stanford University.

Sasha Lascar is a junior at Stanford University, majoring in Mechanical Engineering 